\title{
Aplikasi Directional Coupler Serat Optik sebagai Sensor Pergeseran
}

\author{
Yono Hadi Pramono* dan Ali Yunus Rohedi \\ Jurusan Fisika-FMIPA, Institut Teknologi Sepuluh Nopember \\ Kampus ITS Sukolilo, Surabaya 61111 \\ Samian \\ Departemen Fisika-FMIPA, Universitas Airlangga \\ Kampus C Unair Jl. Mulyorejo Surabaya
}

\begin{abstract}
Intisari
Telah dilakukan eksperimen directional coupler serat optik multimode hasil fabrikasi sendiri sebagai sensor pergeseran mikro berbasis teknik modulasi intensitas dengan teknik yang sederhana. Analisis performansi sensor menggunakan pendekatan berkas Gaussian. Eksperimen menggunakan sumber laser He-Ne $(632,8 \mathrm{~nm} ; 1$ $\mathrm{mW}$ ), detektor OPT-101 (Burr Brown) untuk mendeteksi perubahan daya optik akibat pergeseran obyek (cermin front silvered) serta mikrovoltmeter (Leybold) untuk membaca tegangan keluaran detektor. Pergeseran obyek dilakukan dengan resolusi $5 \mu \mathrm{m}$. Hasil eksperimen menunjukkan performansi sensor yang cukup baik, mampu mendeteksi pergeseran obyek sampai rentang 3,1 mm, daerah kerja sensor $0-1,3 \mathrm{~mm}$ dan sensitivitas sebesar $19,3 \mu \mathrm{W} / \mathrm{mm}$.
\end{abstract}

KATA KUNCI: directional coupler, serat optik multimode, sensor pergeseran

\section{PENDAHULUAN}

Serat optik merupakan media transmisi cahaya yang dapat diaplikasikan sebagai sensor untuk pengukuran beragam parameter seperti pergeseran, suhu, tekanan, kelembaban, laju aliran fluida, laju rotasi, konsentrasi suatu zat, medan listrik, medan magnet, serta analisis kimia. Keunggulan serat optik sebagai suatu sensor antara lain adalah tidak kontak langsung dengan obyek pengukuran, tidak menggunakan listrik sebagai isyarat, akurasi pengukuran yang tinggi, relatif kebal terhadap induksi listrik maupun magnet, dapat dimonitor dari jarak jauh, dapat dihubungkan dengan sistem komunikasi data melalui perangkat antar muka (interface) serta dimensi yang kecil dan ringan. Prinsip kerja dari serat optik sebagai sensor berbasis pada modulasi intensitas, modulasi panjang gelombang dan modulasi fase cahaya sebagai isyarat [1].

Aplikasi serat optik sebagai sensor telah banyak digunakan pada sistem kontrol di industri [2], sistem monitoring pada deformasi bahan [3], strain, temperatur [4], tekanan dan berat benda yang bergerak [5] dan masih banyak lagi ragam aplikasi serat optik sebagai sensor. Aplikasi serat optik sebagai sensor tekanan, berat benda, temperatur, strain maupun vibrasi bertumpu pada kinerja serat optik sebagai sensor pergeseran dengan memanfaatkan daerah kerja sensor pergeseran tersebut.

Eksperimen serat optik sebagai sensor pergeseran berbasis pada modulasi intensitas telah dilakukan dengan memanfaatkan rugi (losses) kopling serat optik ke serat optik meng-

*E-MAIL: yono@physics.its.ac.id gunakan sumber LED [6]. Juga telah dilakukan menggunakan bundle serat optik multimode [7] dan single-mode [8] dengan hasil yang cukup baik tetapi losses-nya tinggi. Metode lain dengan losses yang lebih rendah dilakukan menggunakan directional coupler serat optik singlemode berbasis modulasi fase yang menghasilkan sensitivitas yang tinggi tetapi jangkauannya rendah [9].

Dalam penelitian ini, eksperimen directional coupler sebagai sensor pergeseran berbasis modulasi intensitas dilakukan dengan teknik yang sederhana, menggunakan directional coupler serat optik plastik multimode hasil fabrikasi sendiri dari bahan serat optik plastik (POF) step index multimode tipe FD620-10 yang mudah diperoleh di pasaran. Analisis performansi directional coupler serat optik plastik multimode sebagai sensor pergeseran menggunakan pendekatan berkas Gaussian.

\section{METODOLOGI PENELITIAN}

\section{A. Desain Directional Coupler Sebagai Sensor Pergeseran}

Desain directional coupler sebagai sensor pergeseran diperlihatkan melalui skema pada Gambar 1. Prinsip kerja directional coupler sebagai sensor pergeseran berbasis modulasi intensitas adalah sebagai berikut. Port sensing directional coupler bertindak sebagai pengumpan sekaligus penerima berkas cahaya pantulan dari obyek yang berbentuk cermin datar. Pergeseran cermin (z) akan menyebabkan perubahan daya optik yang diterima oleh port sensing. Perubahan daya optik tersebut dapat terdeteksi melalui port deteksi. 


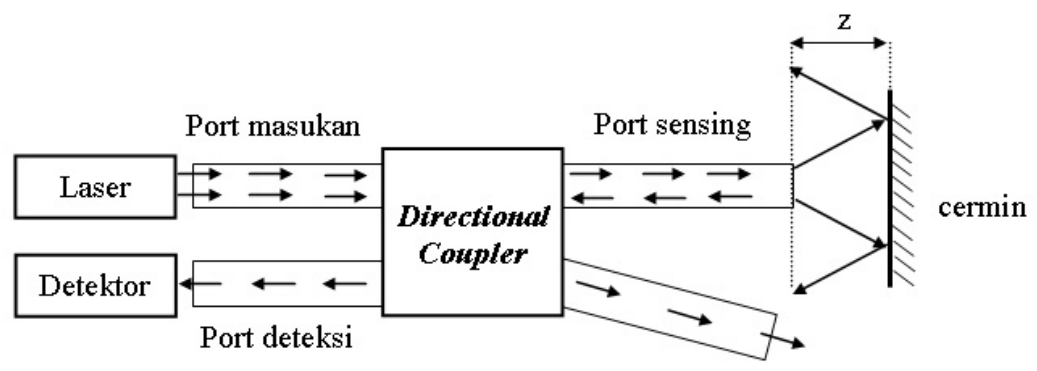

Gambar 1: Desain directional coupler sebagai sensor pergeseran
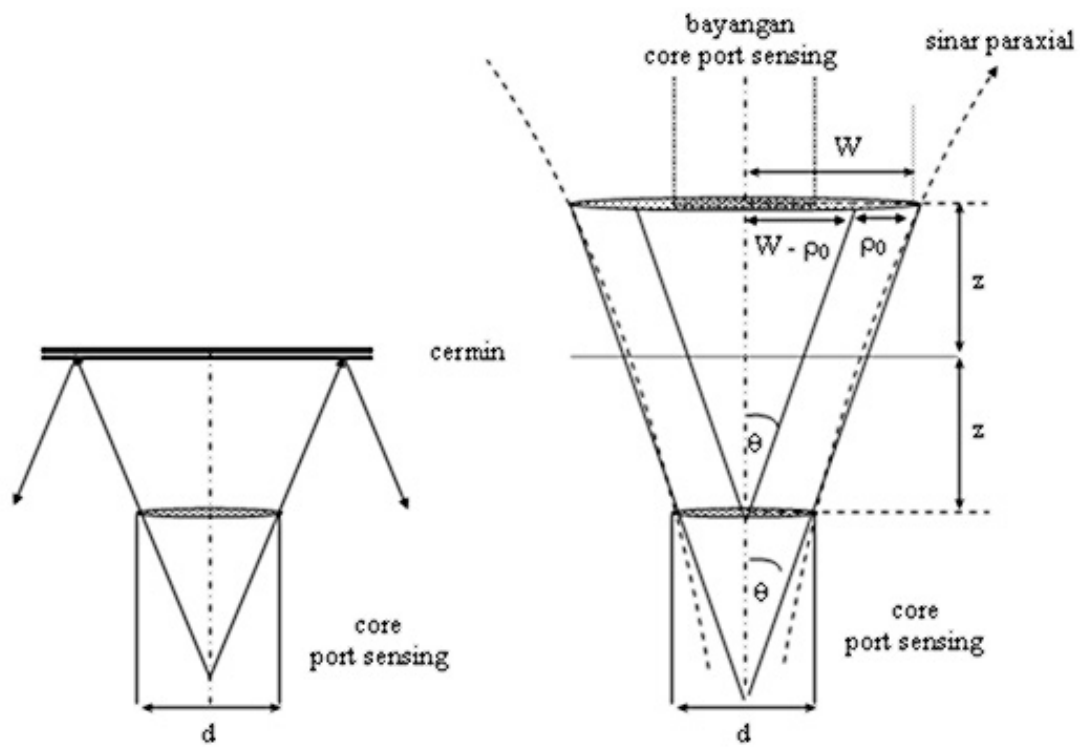

Gambar 2: Skema berkas cahaya pantulan dari cermin yang diterima core port sensing

Karena sumber yang digunakan adalah laser yang mempunyai berkas keluaran berbentuk Gaussian, maka analisis perubahan daya optik pada port sensing akibat pergeseran cermin dilakukan menggunakan pendekatan berkas Gaussian. Daya optik yang diterima oleh bidang lingkaran dengan jarijari $\rho_{\circ}$ tegak lurus terhadap sumbu berkas Gaussian dinya takan melalui Pers.(1) [10].

$$
P=P_{\circ}\left[1-\exp \left(-\frac{2 \rho_{\circ}}{W^{2}(z)}\right)\right]
$$

dengan $\mathrm{P}_{\circ}$ dan $\mathrm{W}(\mathrm{z})$ masing-masing menyatakan daya optik total dan jari-jari berkas Gaussian. Sedangkan z menya takan posisi bidang lingkaran penerima berkas terhadap sumber, dalam hal ini port sensing sebagai pengumpan berkas. Karena port sensing berperan sebagai pengumpan sekaligus bidang penerima berkas pantulan dari cermin, maka posisi pengumpan terhadap penerima berkas menjadi $2 \mathrm{z}$.

Untuk mendapatkan hubungan antara jari-jari berkas (W) terhadap pergeseran cermin (z), digunakan bantuan geometri dengan metode bayangan seperti diperlihatkan pada Gambar 2. Melalui asumsi bahwa sinar paraxial yang merupakan bentuk berkas sesungguhnya berhimpit dengan selubung keru- cut berkas pendekatan, maka dari geometri yang diperlihatkan pada Gambar 2, diperoleh hubungan seperti ditunjukkan Pers.(2).

$$
W=2 z \tan (\theta)+\rho_{\circ}
$$

Substitusi Pers.(2) ke Pers.(1) diperoleh persamaan sebagai berikut.

$$
P=P_{\circ}\left\{1-\exp \left[-\frac{2}{(c z+1)^{2}}\right]\right\}
$$

dengan $\mathrm{c}=4 \tan (\theta) / \mathrm{d}, \mathrm{d}$ adalah diameter core serat optik port sensing, sedangkan sudut $\theta$ berkaitan dengan tingkap numerik serat optik dengan hubungan $\theta=\arcsin (\mathrm{NA})$.

\section{B. Setup Eksperimen}

Susunan peralatan eksperimen directional coupler sebagai sensor pergeseran diperlihatkan pada Gambar 3. Sumber yang digunakan adalah laser He-Ne panjang gelombang $632,8 \mathrm{~nm}$ $(1 \mathrm{~mW})$, detektor OPT 101 (Burr Brown) untuk mendeteksi 


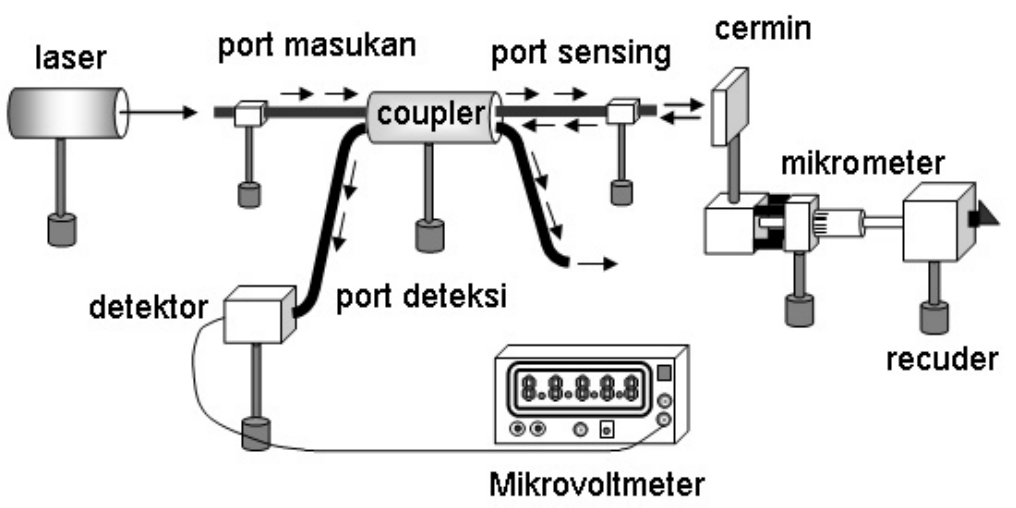

Gambar 3: Susunan alat karakterisasi sensor pergeseran mikro

daya optik pada port deteksi, mikrovoltmeter (Leybold) untuk membaca tegangan keluaran detektor. Untuk menggeser cermin (front silvered,46320, Leybold) digunakan mikrometer skrup dengan ketelitian 0,01 mm yang dihubungkan secara mekanis dengan recuder melalui poros putarnya, sehingga satu putaran recuder menghasilkan pergeseran $5 \mu \mathrm{m}$. Directional coupler yang digunakan difabrikasi dari serat optik plastik Tipe FD-620-10 diameter core $950 \mu \mathrm{m}$ dengan nilai rata-rata parameter $\mathrm{CR}=0,319$, toleransi $\mathrm{CR}=11 \%, \mathrm{C}_{t}=28$ $\mathrm{dB}, \mathrm{L}_{\text {ins }}=4,2 \mathrm{~dB}$ dan $\mathrm{L}_{e}=2,6 \mathrm{~dB}$.

Eksperimen dilakukan dengan mencatat tegangan keluaran detektor setiap cermin digeser sebesar $5 \mu \mathrm{m}$ menjauhi port sensing. Pencatatan dilakukan sampai pergeseran obyek tidak menghasilkan perubahan daya optik. Tegangan keluaran detektor yang terbaca kemudian dikonversi ke daya optik. Konversi dilakukan dengan memvariasi daya optik keluaran laser dengan cara menempatkan sepasang polarisator diantara laser dan detektor. Sepasang polarisator berfungsi memvariasi intensitas cahaya keluaran laser melalui perubahan sudut polarisasi. Slop grafik linier hasil plot antara daya optik terhadap tegangan keluaran detektor merupakan faktor konversi.

\section{HASIL DAN PEMBAHASAN}

Hasil eksperimen directional coupler sebagai sensor pergeseran berupa data tegangan keluaran detektor sebagai fungsi pergeseran cermin. Faktor konversi yang dihasilkan sebesar 0,0108 $\mathrm{mW} / \mathrm{V}$. Setelah tegangan keluran detektor dikalikan faktor konversi, plot data eksperimen daya optik sebagai fungsi pergeseran cermin dan grafik teori yaitu Pers.(3) diperlihatkan pada Gambar 4.

Nilai $\mathrm{P}_{\circ}$ dan $\mathrm{c}$ pada hasil plot Pers.(3) masing-masing adalah $45,33 \mu \mathrm{W}$ dan $0,001 \mu \mathrm{m}^{-1}$. Standart deviasi kedua grafik adalah 0,99 . Gambar 4 memperlihatkan pola kedua grafik yaitu data eksperimen dan teori hampir sesuai.

Dari nilai c yang dihasilkan, dapat dihitung nilai NA serat optik yang digunakan melalui hubungan $\mathrm{c}=4 \tan (\theta) / \mathrm{d}$ dan $\theta=\arcsin (\mathrm{NA})$. Hasil perhitungan menunjukkan nilai $\mathrm{NA}=$

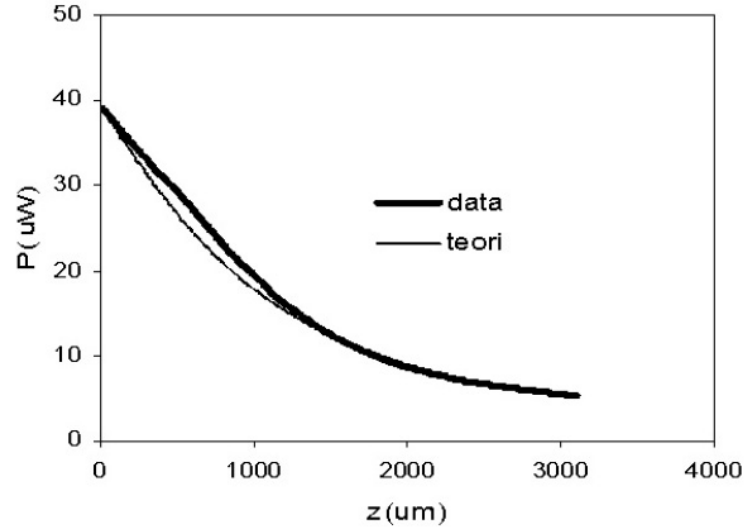

Gambar 4: Grafik plot data eksperimen dan teori.

0,23 . Nilai tersebut masih belum memenuhi nilai NA serat optik plastik multimode antara 0,3 - 0,5 [1]. Masih belum terpenuhinya nilai NA tersebut karena pendekatan yang dilakukan pada penentuan hubungan antara jari-jari berkas terhadap pergeseran cermin yaitu asumsi bahwa berkas Gaussian (dalam hal ini sinar paraxial) berhimpit dengan selubung kerucut bentuk berkas pendekatan tidak sepenuhnya tepat. Seperti diketahui bahwa sifat sinar paraxial untuk daerah z kecil, sudut $\theta$ yang dibentuk oleh garis singgung sinar paraxial terhadap sumbu serat lebih kecil dari pada sudut $\theta$ yang dibentuk oleh selubung kerucut berkas pendekatan terhadap sumbu serat. Untuk $\mathrm{z}$ yang lebih besar, sudut $\theta$ semakin besar $(\theta$ sebagai fungsi $\mathrm{z}$ ), sedangkan untuk $\mathrm{z}$ yang sangat besar, sudut $\theta$ akan sama dengan sudut $\theta$ yang dibentuk oleh selubung kerucut berkas pendekatan. Walaupun demikian, pendekatan tersebut dapat menyederhanakan formulasi dalam menganalsis perubahan daya optik terhadap pergeseran cermin.

Sebagai sensor pergeseran, maka hubungan variabel sensor yaitu daya optik dan pergeseran haruslah linier. Daerah linier tersebut merupakan daerah kerja dari sensor. Karena itu dilakukan pemilihan daerah yang diasumsikan linier dari data eksperimen directional coupler sebagai sensor pergeseran, kemudian menguji linieritas daerah yang diasumsikan, hasilnya diperlihatkan pada Gambar 5. 


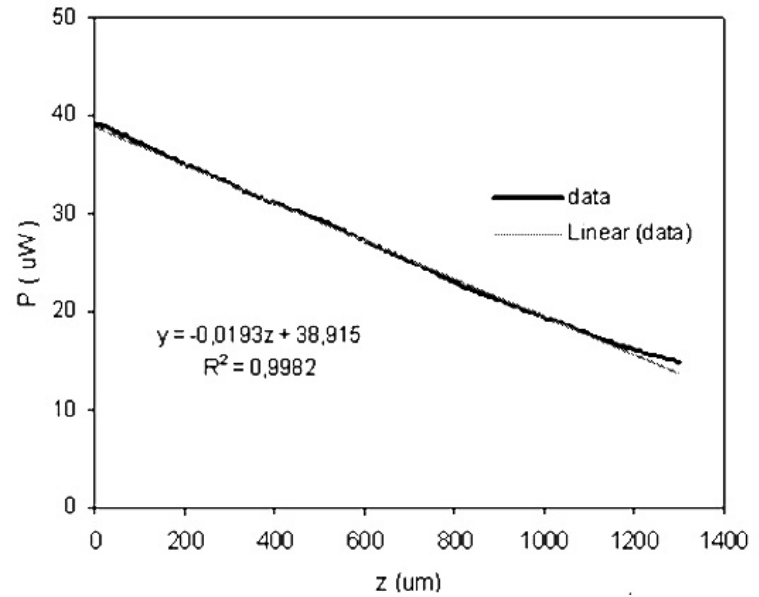

Gambar 5: Daerah linier data eksperimen

Uji linieritas menghasilkan nilai $\mathrm{R}^{2}$ mendekati 1 , sehingga hubungan antara daya optik terhadap pergeseran pada daerah yang dipilih adalah linier. Slop grafik linier menunjukkan sensitivitas sensor. Dengan demikian sensitivitas directional coupler sebagai sensor pergeseran adalah 19,3 $\mu \mathrm{W} / \mathrm{mm}$. Dari nilai sensitivitas sensor yang dihasilkan, secara teoritis, jika menggunakan detektor OPT 101 yang mempunyai kepekaan sampai $10 \mathrm{nW}$, sensor mampu mendeteksi pergeseran sampai 0,5 mikrometer dengan daerah linier (daerah kerja sensor) antara $0-1,3 \mathrm{~mm}$.
Dari hasil yang diperoleh, directional coupler mempunyai performansi yang cukup baik sebagai sensor pergeseran dengan parameter sensor seperti ditunjukkan pada Tabel 1 .

TABEL I: Parameter directional coupler sebagai sensor pergeseran

\begin{tabular}{ll}
\hline \hline Daya sumber & $1 \mathrm{~mW}$ \\
Resolusi pergeseran alat & $5 \mu \mathrm{m}$ \\
Jangkauan & $3,1 \mathrm{~mm}$ \\
Daerah kerja & $0-1,3 \mathrm{~mm}$ \\
Sensitivitas & $19,3 \mu \mathrm{W} / \mathrm{mm}$ \\
\hline \hline
\end{tabular}

Performansi directional coupler sebagai sensor pergeseran khususnya sensitivitas dan jangkauan masih dapat ditingkatkan jika menggunakan directional coupler yang memiliki nilai coupling ratio yang lebih tinggi (nilai maksimal coupling ratio directional coupler serat optik multimode sebesar $0,5)$ serta excess loss yang lebih rendah. Peningkatan sensitivitas serta stabilitas sistem pengukuran yang tinggi, akan memberikan prospek bagi directional coupler sebagai sensor pergeseran yang mampu mendeteksi pergeseran sampai orde nanometer.

\section{SIMPULAN}

Berdasarkan hasil penelitian dan pembahasan yang telah dijelaskan, maka dapat disimpulkan bahwa directional coupler serat optik multimode dapat digunakan sebagai sensor pergeseran sampai orde mikrometer dengan performansi yang cukup baik.
[1] Krohn, D.A, Fiber Optik Sensor, Fundamental and Aplication $\left(3^{r d}\right.$, ISA, New York, 2000.)

[2] Hoss, R.J, Fiber Optics(2ed, Prentice-Hall, New Jersey, 1993.)

[3] Sklodowski, M., Theory and Aplication of Fiber Optics Sensor to Settlement of Historical Structure, Procceding AMAS Workshop, Jadwisun, 2003.

[4] Inaudi, D., Glisic, B., Field Aplication of Fiber Optic and Temperature Monitoring, Procceding International Conference Optoelectronic Sensor Based Monitoring In Geo-Enginering, Nanjing, 2005.

[5] Ahmad, S.J., A Low Cost Fiber Opric Weigh-In-Motion Sensor (SHRP National Research Council, Washington, 1990)
[6] Svyryd, N.N, Osorno, S., Salazar, M.E.E, Revista Mexicana de Fisica S 52, 2 (2006).

[7] Yasin, M., Harun, W.S., Abdul Rasyid, H.A., Kusminarto, Karyono dan H. Ahmad, Laser Physics 10, 1002 (2007).

[8] A. Rostami, M. Noshad, H. Hedayati, A. Ghanbari, and TPF. Janabi, IJCSNS 7, 4 (2007).

[9] Baruch, M.C., Gerdt, D.W., Adkins, C.M., Fiber Optic Couplers Displacement Sensor, Procceding SPIE 2002

[10] Saleh, B.H.A., Teich, M.C., Fundamental of Photonics (John Wiley \& Sons, Inc. 1991.) 